\title{
COMPARISON OF L2- AND L1-NORM TO PERFORM THE INVERSION OF TRAVEL-TIME CURVES USING NONHYPERBOLIC MULTIPARAMETRIC APPROXIMATIONS WITH UNIMODAL AND MULTIMODAL BEHAVIOR
}

\author{
Nelson Ricardo Coelho Flores Zuniga ${ }^{1}$, Fernando Brenha Ribeiro ${ }^{1}$ and Viatcheslav Ivanovich Priimenko ${ }^{2}$
}

\begin{abstract}
Many nonhyperbolic multiparametric travel-time approximations were developed in the last decades. As the seismic inversion became more popular, there were studies concerning the objective function of this kind of equations. Many of these approximations have a unimodal behavior where there is only the global minimum region while others have a multimodal statistical distribution with the global minimum region and one or more local minimum regions. However, two approximations showed both unimodal and multimodal behaviors to vary depending on the model. As the variation of the model generates only subtle distortions concerning the topology of the objective function, a method which can make this topology more abrupt is a solution to perform a more effective inversion. This kind of information can be reached using the L1-norm rather than the L2-norm, and with the comparison of the two norms for both reflection events (PP and PS) of the model and both approximations, it is possible to understand which kind of improvement it brings concerning the complexity and accuracy analysis.
\end{abstract}

Keywords: objective function, nonhyperbolicity, probability distribution.

RESUMO. Várias aproximações não-hiperbólicas multiparamétricas de tempos de trânsito foram desenvolvidas nas últimas décadas. Com a inversão sísmica se tornando cada vez mais popular, houve estudos relacionados à função objetivo desse tipo de equação. Muitas dessas aproximações apresentam um comportamento unimodal, onde há apenas uma região de mínimo global, enquanto outras apresentam uma distribuição estatística multimodal, com a região de mínimo global e uma ou mais regiões de mínimos locais. Entretanto, duas aproximações mostraram ambos os comportamentos, unimodal e multimodal, variando a depender do modelo. Como a variação do modelo gera apenas distorções sutis com relação à topologia da função objetivo, um método no qual é capaz de tornar a topologia mais abrupta é uma forma de realizar a inversão com maior efetividade. Este tipo de informação pode ser obtido usando a norma L1 ao invés da norma L2, e com a comparação das duas normas para ambos os eventos de reflexão (PP e PS) do modelo e para ambas as aproximações, é possível entender qual tipo de melhoria é alcançada com relação à análise de complexidade e de precisão.

Palavras-chave: função objetivo, não-hiperbolicidade, distribuição probabilística.

\footnotetext{
${ }^{1}$ Universidade de São Paulo, Instituto de Astronomia, Geofísica e Ciências Atmosféricas (IAG-USP), Departamento de Geofísica, Rua do Matão, 1226 - Butantã, 05508-090, São Paulo, SP, Brazil - E-mails: nelson.zuniga@iag.usp.br, fernando.brenha@iag.usp.br

${ }^{2}$ Universidade Estadual do Norte Fluminense Darcy Ribeiro, Laboratório de Engenharia e Exploração de Petróleo (LENEP-UENF), Av. Brennand, s/n, Rod. Amaral Peixoto, km 163, Imboassica, Macaé, 27925-535 Rio de Janeiro, RJ, Brazil - E-mail: slava@lenep.uenf.br
} 


\section{INTRODUCTION}

Concerning the large offsets with layered media, the converted PS waves and OBN (Ocean Bottom Nodes) data, there is a significant challenge during the velocity analysis step, once these three characteristics increase the nonhyperbolicity. For this reason, there were developed many nonhyperbolic approximations to deal with many causes of the nonhyperbolicity (e.g. Malovichko, 1978; Muir \& Dellinger, 1985; Alkhalifah \& Tsvankin, 1995; Li \& Yuan, 2001; Ursin \& Stovas, 2006; Blias, 2009).

In recent works (Zuniga et al, 2015, 2016a, 2016b, 2017; Zuniga, 2017), the objective function analysis was used to understand the complexity of these approximations, and helps to understand their behavior during the inversion procedure. Some approximations presented a unimodal statistical distribution (e.g. Malovichko, 1978; Alkhalifah \& Tsvankin, 1995) due to their simplicity, while other approximations showed a multimodal behavior (e.g. Muir \& Dellinger, 1985; Li \& Yuan, 2001; Ursin \& Stovas, 2006; Blias, 2009). However, the approximations proposed by Ursin \& Stovas (2006) and Blias (2009) presented both unimodal and multimodal behaviors, varying according the model, as observed by Zuniga et al. (2018). More tests were performed for deep-water models and showed very well results concerning a better accuracy and lower processing time (Zuniga et al, 2019).

Since there is a substantial range of models in the thresholds of the statistical distribution behaviors, it is difficult to define in which kind of model these approximations must be considered unimodal or multimodal. Thus, to consider these two approximations always unimodal, it is necessary to find a way in which it is possible to make a topology of the objective function less complex. Therefore, it must be simpler enough to suppress the local minimum regions and the more subtle features.

To perform this kind of enhance, it shall be used the L1-nom rather than the L2-norm. The L2-norm, also known as the least squares, makes a more delineated objective function topology due to it minimizing the sum of the square of the difference between the targeted value and the calculated value. Otherwise, the least absolute deviation (L1-norm) minimizes the error between the observed and the calculated value (Khaleelulla, 1982; Bourbaki, 1987).

So, with the Model defined and its travel-time curves generated as a direct problem, it is possible to perform the minimization between the calculated curves with the two approximations and the observed curves. The objective function can be analyzed by a residual function map where it is possible to study its topological structure. Therefore, for the Ursin \& Stovas (2006) and Blias (2009) approximations and for both conventional and converted wave events, it is possible to test the L2-norm and the L1-norm, and find out the differences between them, and define if it is more suitable to work with L1-norm for this kind of travel-time approximation.

\section{MODEL}

The Model studied here (Table 1), is an offshore layered model, based on a Campos Basin reservoir with a sandstone reservoir ( $V_{P}=2952 \mathrm{~m} / \mathrm{s}$ and $V_{S}=1593 \mathrm{~m} / \mathrm{s}$ ) beneath the $5^{\text {th }}$ layer (the shale sealing layer).

The soft increase of the P-wave and S-wave velocities can be easier observed with the velocities profile (Fig. 1). With the parameters of the Model it is possible to produce the ray tracing and extract the travel-time curves of the events PP and PS (Margrave, 2000 and 2003; Thorbecke \& Draganov, 2012), as it can be observed in Figure 2.

Table 1 - The parameters of the Model: Layer thickness $(\Delta z)$, P-wave velocity $\left(V_{P}\right)$, S-wave velocity $\left(V_{S}\right)$ and $V_{P} / V_{S}$ ratio.

\begin{tabular}{ccccc}
\hline Layer & $\Delta z(\mathrm{~m})$ & $V_{P}(\mathrm{~m} / \mathrm{s})$ & $V_{S}(\mathrm{~m} / \mathrm{s})$ & $V_{P} / V_{S}$ \\
\hline Water & 1052 & 1500 & 0 & - \\
1 & 298 & 1930 & 643 & 3.00 \\
2 & 559 & 2127 & 1134 & 1.88 \\
3 & 311 & 2357 & 1202 & 1.96 \\
4 & 161 & 2554 & 1390 & 1.84 \\
5 & 77 & 2733 & 1403 & 1.95 \\
\hline
\end{tabular}

\section{The nonhyperbolic multiparametric travel-time approximations with multimodal and unimodal behavior}

The approximation developed by Ursin \& Stovas (2006) uses the heterogeneity parameter $S$ also used by Malovichko (1978) for the shifted hyperbola which were adapted from the hyperbola equation proposed by Dix (1955). However, for this approximation (Eq. 1), the authors proposed that the $S$ parameter is expressed in a quasi-acoustic case, as a function of the Thomsen anisotropic parameters (Thomsen, 1986).

$$
t=\sqrt{t_{0}^{2}+\frac{x^{2}}{v^{2}}-\frac{(S-1) x^{4}}{4 v^{4}\left(t_{0}^{2}+\frac{(S-1)}{2} \frac{x^{2}}{v^{2}}\right)}}
$$




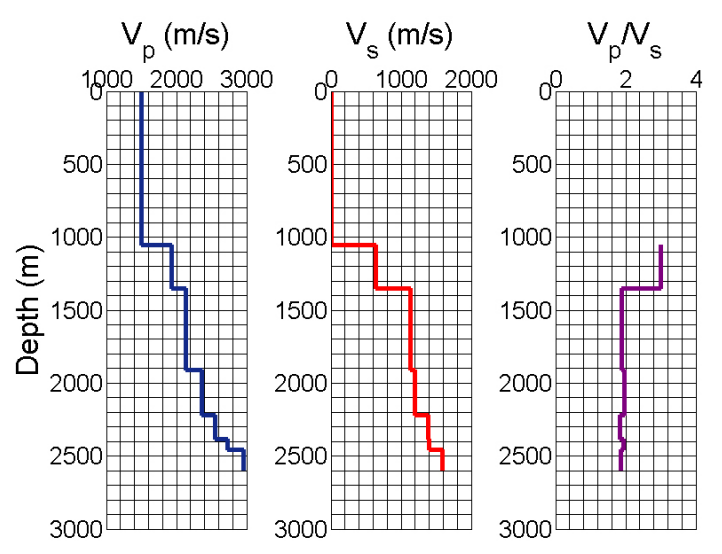

Figure 1 - P-wave velocity $\left(V_{P}\right)$, S-wave velocity $\left(V_{S}\right)$ and $V_{P} / V_{S}$ ratio profiles of the Model.
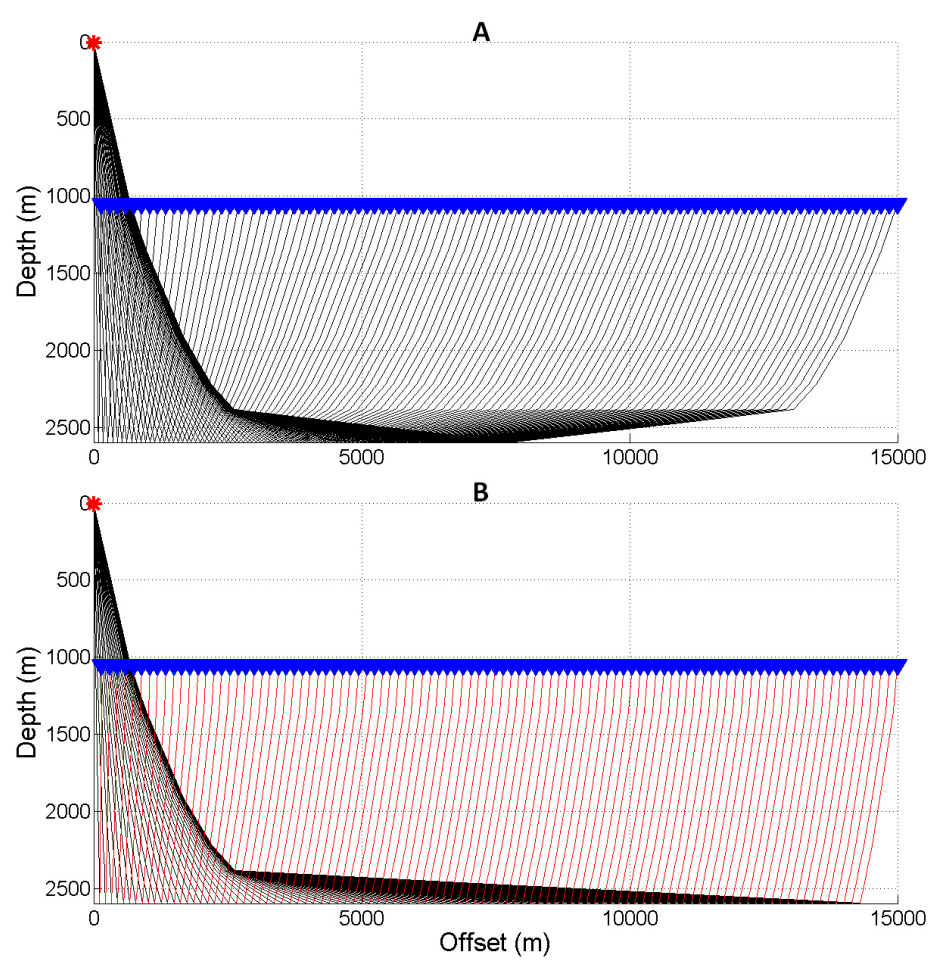

Figure 2 - Ray tracing of the (A) PP wave reflection event and (B) PS wave reflection event of the Model.

The $S$ parameter depends on the $\mu_{4}$ and $\mu_{2}$ by the relation $S=\mu_{4} / \mu_{2}^{2}$, where $\mu_{j}(j=2,4)$ is the $j$-th velocity momentum (Eq. 2).

$$
\mu_{j}=\sum_{k=1}^{n} t_{k} v_{k}^{j} / \sum_{k=1}^{n} t_{k}
$$

and $v_{k}$ is the interval velocity of the $k$-th layer and $t_{k}$ is the travel-time of the $k$-th layer.
Blias (2009) proposed an approximation (Eq. 3) which also uses the heterogeneity parameter $S$, proposed by Malovichko (1978). Different than the Equation 1, this approximation was developed performing several numerical tests related to the walkway vertical seismic profile (VSP).

$$
t=\frac{1}{2} \sqrt{t_{0}^{2}+\frac{1-\sqrt{S-1}}{v^{2}}} x^{2}+\frac{1}{2} \sqrt{t_{0}^{2}+\frac{1+\sqrt{S-1}}{v^{2}} x^{2}}
$$


Once both approximations showed both statistical distributions in previous works, they must be tested concerning the L1-norm to observe if they behave sufficiently better than the L2-norm aiming to suppress the local minimum region.

\section{Complexity analysis of the objective function for L2- and L1-norm}

The complexity analysis by the observation of residual function maps (RFM) is necessary to understand the complexity of the topology of the objective function (Larsen, 1999; Kurt, 2007). The RFM shows the relation between the additional parameter (the $S$ parameter in this case) with the velocity of the event, while the third dimension of the hyperplane represents the values of minimum. As the $t_{0}$ is the less sensible variable, it was fixed as constant after the recovering of the parameters during the inversion.

A norm is the total length of a set of vectors in a vector space or the total size of a set of matrices in a matrix space. The norm is a function which assigns a strictly positive length to each vector in a vector space, or a positive size to each matrix in a matrix space, being not valid to zero vector or zero matrix (Khaleelulla, 1982; Bourbaki, 1987). The L2-norm also known as least squares method sums the square of the difference between the observed value and the estimated one (Eq. 3).

$$
R^{2}=\sum_{j=1}^{n}\left(t_{j o b s}-t_{j e s t}\right)^{2}
$$

On the other hand, the L1-norm, known as least absolute deviation aims to minimize the sum of the absolute difference between the observed value and the estimated one (Eq. 4).

$$
R=\sum_{j=1}^{n}\left|t_{j o b s}-t_{j e s t}\right|
$$

Where $R$ is the error between the observed and estimated value, $t_{j o b s}$ and $t_{j e s t}$ are, respectively, the observed and the estimated travel-time for a value $j$-th.

In this work, the focus is to observe the variation of behavior between L2- and L1-norm for each reflection travel-time event (PP and PS) with the selected approximation.

It is possible to observe for each approximation and each event whether the use of L1-norm affects the statistical distribution concerning the objective function by analyzing the variation of behavior between L2- and L1-norm for each reflection event and for each approximation.

The RFM applied to both norms provides information to have a deeper understanding concerning the optimization algorithm (global or local search) that should be used for this kind of problem.

It can be observed in Figure 3A, that for the PP wave reflection event the topology of the objective function has some features that cannot be observed in Figure $3 \mathrm{~B}$, with the approximation proposed by Ursin \& Stovas (2006). As these subtle features are suppressed by the use of the L1-norm, the Figure 3B showed a unimodal behavior, and a narrower global minimum region, with a more abrupt behavior of the topology of the objective function.

For the converted wave event, also for the Ursin \& Stovas (2006) approximation, it is possible to observe the same kind of variation when the L1-norm is applied. Before (Fig. 4A), it is clearly observed a global and a local minimum region, while in the Figure $4 \mathrm{~B}$, it is shown a unimodal behavior with the local minimum region completely suppressed, a narrower global minimum region and a little more abrupt topological structure.

For the approximation proposed by Blias (2009), it is possible to observe a more complex topology than the one proposed by Ursin \& Stovas (2006). However, the same behaviors were observed. In the conventional reflection event, the Figure $5 B$ showed a narrower global minimum region than the Figure $5 \mathrm{~A}$, with no local minimum region and with a little more abrupt structure.

As a similar behavior of the Figure 5 , the Figure $6 \mathrm{~B}$ showed a full suppression of the local minimum region and a narrower global minimum region. However, the variation of the abruptness is more intense in this case.

\section{Residual travel-time comparison and accuracy analysis}

The comparison of nonhyperbolic approximations are being performed since the beginning of the decade (Aleixo \& Schleicher, 2010; Golikov \& Stovas, 2012). However, there is no works comparing the accuracy of nonhyperbolic travel-time approximations between the L2- and L1-norm.

The accuracy analysis is performed by comparing the calculated curve to the observed curve. After the calculated curve fits to the observed one, it is analyzed the error between them.

After perform the inversion, with the parameters recovered, it is possible to observe the relative travel-time errors. In Figure $7 \mathrm{~A}$, it is possible to observe for the conventional PP reflection event, that both approximations showed more accurate results with the L1-norm than with the L2-norm. The same observation can be done in Figure 7B; the L1-norm presents more accurate results than the L2-norm. However, in Figure 7B, 


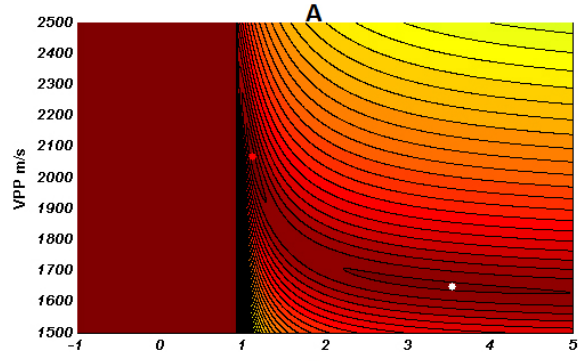

B

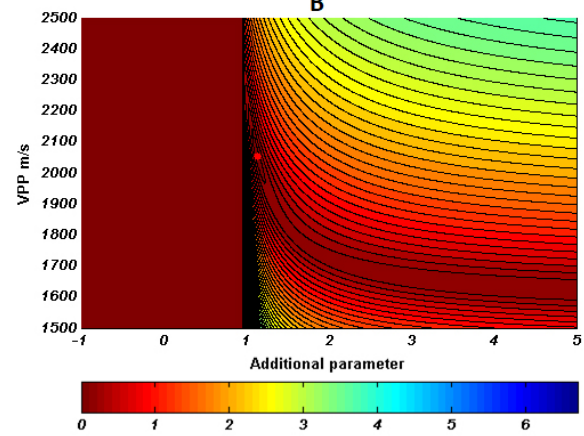

Figure 3 - Residual function maps to demonstrate the complexity of the approximation proposed by Ursin \& Stovas (2006) for the PP wave reflection event with (A) L2-norm and (B) L1-norm. Red dispersions represent the global minimum region and the white dispersions represent the local minimum region.
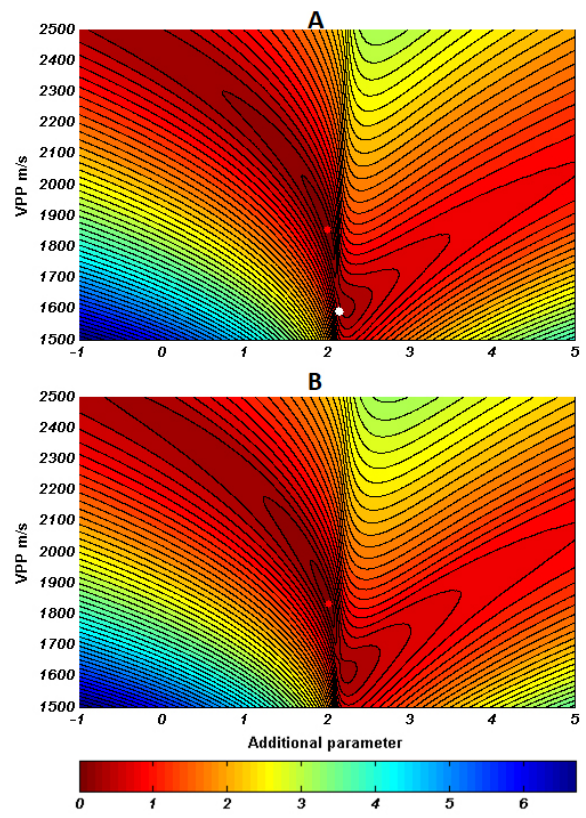

Figure $\mathbf{5}$ - Residual function maps to demonstrate the complexity of the approximation proposed by Blias (2009) for the PP wave reflection event with (A) L2-norm and (B) L1-norm. Red dispersions represent the global minimum region and the white dispersions represent the local minimum region.

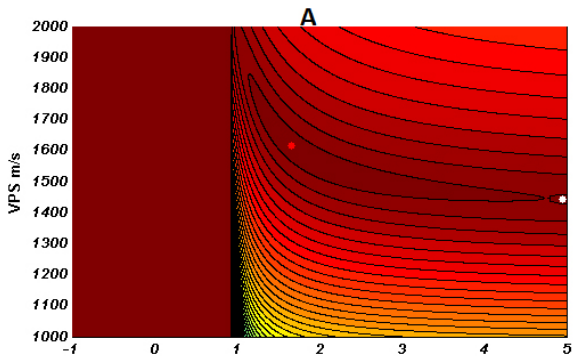

B

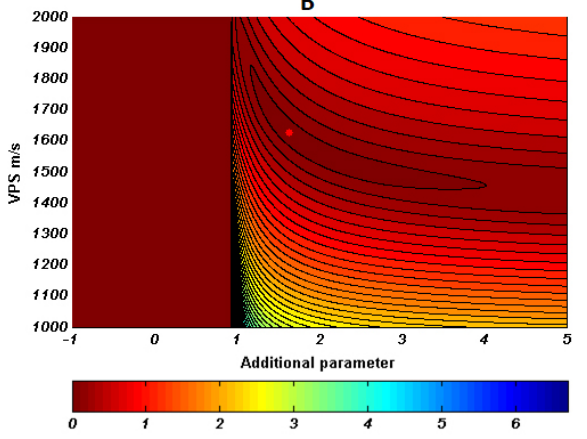

Figure 4 - Residual function maps to demonstrate the complexity of the approximation proposed by Ursin \& Stovas (2006) for the PS wave reflection event with (A) L2-norm and (B) L1-norm. Red dispersions represent the global minimum region and the white dispersions represent the local minimum region.
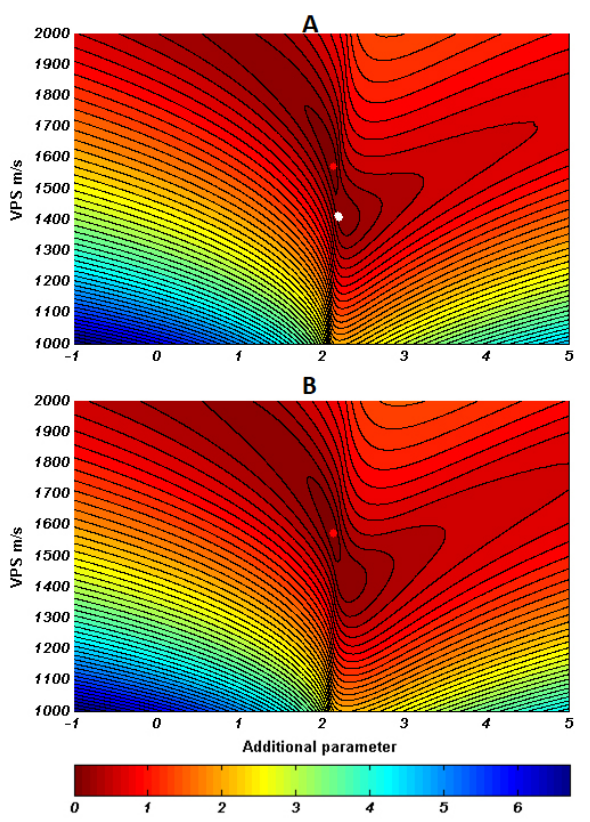

Figure $\mathbf{6}$ - Residual function maps to demonstrate the complexity of the approximation proposed by Blias (2009) for the PS wave reflection event with (A) L2-norm and (B) L1-norm. Red dispersions represent the global minimum region and the white dispersions represent the local minimum region. 

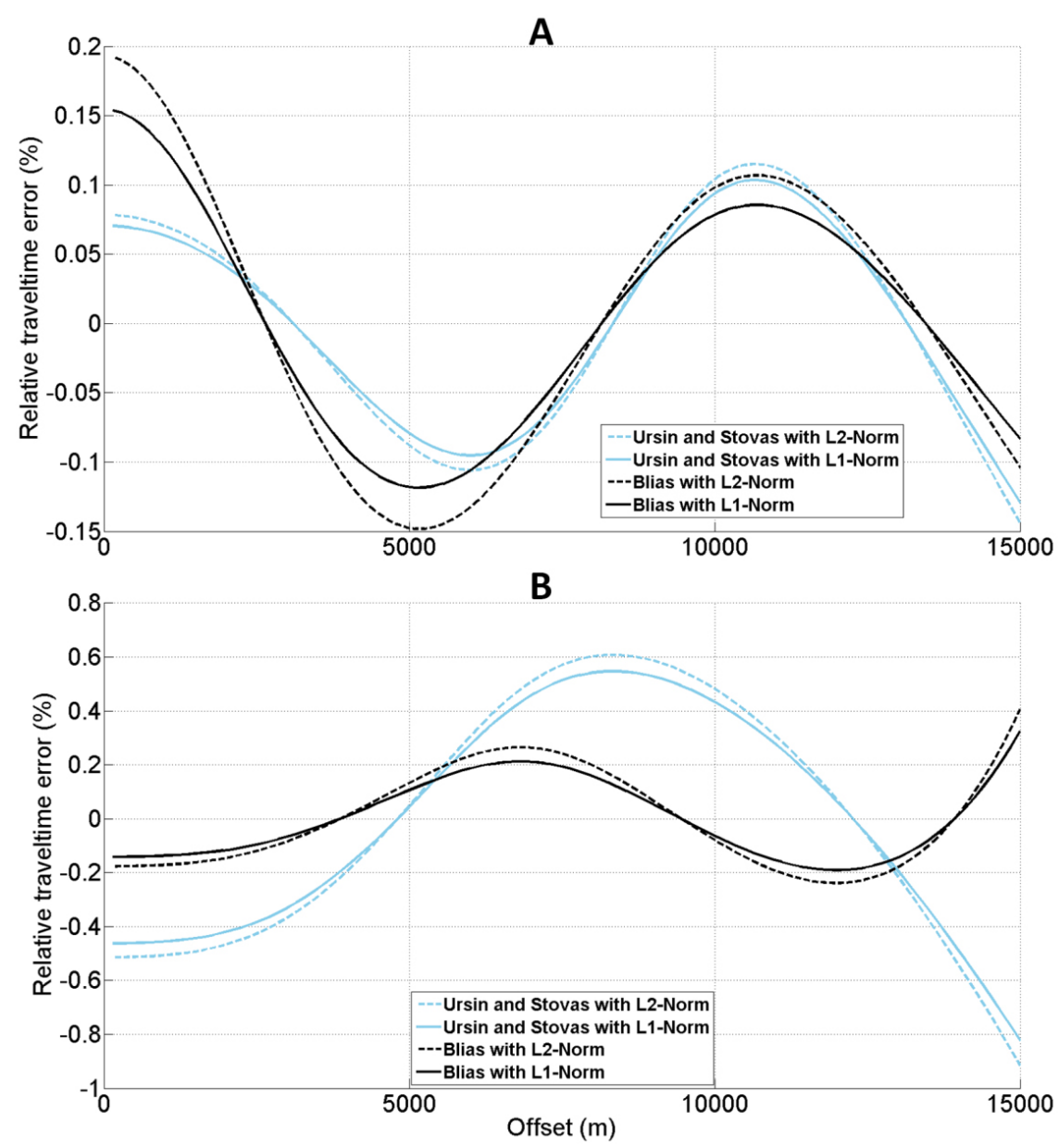

Figure 7-Relative errors in travel-time between the observed curve and the calculated curve with each approximation and each norm for (A) PP wave reflection event and (B) PS wave reflection event. Data for Ursin \& Stovas (2006) and Blias (2009).

the approximation proposed by Blias (2009) presented a much more accurate with both norms than the results shown by Ursin \& Stovas (2006) approximation.

\section{CONCLUSIONS}

In all conditions tested in this work, there was an improvement in using the L1-norm rather than the L2-norm. For both reflection events and both approximations, the L1-norm showed a narrower global minimum region and a more abrupt structure of the objective function with no local minimum region.

The accuracy also increased for both nonhyperbolic approximations and for both reflection events when the L1-norm is used, what shows that even if there was no suppression of the local minimum region it would still bring a enhance in the results, once a narrower global minimum region results in a lower relative travel-time error.

Due to these results, the use of L1-norm clearly is a reliable method to simplify the topology of the objective function of this kind of travel-time approximations and also reach a more accurate global minimum value.

\section{ACKNOWLEDGEMENTS}

This study was financed in part by the Coordenação de Aperfeiçoamento de Pessoal de Nível Superior - Brazil (CAPES) - Finance Code 001 and in part by the Conselho Nacional de Desenvolvimento Científico e Tecnológico - Brazil (CNPq). 


\section{REFERENCES}

ALEIXO R \& SCHLEICHER J. 2010. Traveltime approximations for q-P waves in vertical transversely isotropy media. Geophysical Prospecting, 58: 191-201.

ALKHALIFAH T \& TSVANKIN I.1995. Velocity analysis for transversely isotropic Media. Geophysics, 60: 1550-1566.

BLIAS E. 2009. Long-offset NMO approximations for a layered VTI model: Model study. In: 79th Annual International Meeting. Houston, Texas. Society of Exploration Geophysics, Expanded Abstract, p. 3745-3749.

BOURBAKI N. 1987. Topological vector spaces. Berlin, Springer-Verlag Berlin and Heidelberg, $362 \mathrm{pp}$.

DIX CH. 1955. Seismic velocities from surface measurements. Geophysics, 20: 68-86.

GOLIKOV P \& STOVAS A. 2012. Accuracy comparison of nonhyperbolic moveout approximations for qP-waves in VTI media. Journal of Geophysics and Engineering, 9: 428-432.

KHALEELULLA SM. 1982. Counterexamples in topological vector spaces. 2nd ed, Berlin, Springer-Verlag Berlin and Heidelberg, 184 pp.

KURT H. 2007. Joint inversion of AVA data for elastic parameters by bootstrapping. Computers \& Geosciences, 33(3): 367-382.

LARSEN JA. 1999. AVO Inversion by Simultaneous P-P and P-S Inversion. M.Sc. Thesis, University of Calgary, Department of Geology and Geophysics, Calgary, Canada. 124 pp.

LI XY \& YUAN J. 2001. Converted wave imaging in inhomogeneous, anisotropic media: Part I. Parameter estimation. In: 63rd EAGE Conference. Expanded Abstract, Amsterdam, the Netherlands. v. 1, p. 109.

MALOVICHKO AA. 1978. A new representation of the traveltime curve of reflected waves in horizontally layered media. Applied Geophysics (in Russian), 91(1): 47-53.

MARGRAVE GF. 2000. New seismic modelling facilities in Matlab. CREWES Research Report, 12: 45pp.

MARGRAVE GF. 2003. Numerical methods of exploration seismology with algorithms in MATLAB. CREWES Research Report, 219pp.
MUIR F \& DELLINGER J. 1985. A practical anisotropic system. In: SEP-44. Stanford Exploration Project, p. 55-58.

THOMSEN L. 1986. Weak elastic anisotropy. Geophysics, 51: 1954-1966.

THORBECKE JW \& DRAGANOV D. 2012. Finite-difference modeling experiment for seismic interferometry. Geophysics, 76: H1-H18.

URSIN B \& STOVAS A. 2006. Traveltime approximations for a layered transversely isotropic medium. Geophysics, 71: 23-33.

ZUNIGA NRCF. 2017. Análise comparativa de aproximações não-hiperbólicas dos tempos de trânsito de dados sísmicos multicomponente utilizando tecnologia OBN. Master Dissertation, Universidade de São Paulo, SP, Brazil. 86 pp.

ZUNIGA NRCF, BOKHONOK 0 \& DIOGO LA. 2015. Comparison of nonhyperbolic travel-time approximations for multicomponent seismic data. In: $14^{\text {th }}$ SBGf Congress. Expanded Abstract, Rio de Janeiro, RJ, Brazil. p. 1176-1181.

ZUNIGA NRCF, MOLINA EC \& PRADO RL. 2016a. Inversion of multicomponent seismic data for VTI medium using the globalized Nelder-Mead optimization algorithm. In: 3rd EAGE/SBGf Workshop. Expanded Abstract. Rio de Janeiro, RJ, Brazil.

ZUNIGA NRCF, MOLINA EC \& PRADO RL. 2016b. Inversion of multicomponent seismic data of the Santos Basin. In: Far East Hydrocarbons. Russia, EAGE. Expanded Abstract.

ZUNIGA NRCF, MOLINA EC \& PRADO RL. 2017. Comparison of travel-time approximations for unconventional reservoirs from Santos Basin, Brazil. Brazilian Journal of Geophysics, 35(4): 273-286.

ZUNIGA NRCF, RIBEIRO FB \& PRIIMENKO VI. 2018. Relation between the model and the topography of the objective function in a velocity analysis using a nonhyperbolic multicomponent travel-time approximation. Brazilian Journal of Geophysics, 36(4): 375-384.

ZUNIGA NRCF, RIBEIRO FB \& PRIIMENKO VI. 2019. L2- and L1-norm applied to inversion of nonhyperbolic travel-time. Brazilian Journal of Geophysics, 37(2): 155-161. 